\title{
Navajo in the typology of internally-headed relatives*
}

\author{
Elizabeth Bogal-Allbritten \\ University of Gothenburg
}

\author{
Keir Moulton \\ University of Toronto
}

\begin{abstract}
This paper considers the semantics of Navajo internally-headed relative clauses (IHRCs) with quantified heads. The results of storyboard-based fieldwork show that when the quantifier 'atníi'dóo 'half' occurs in RC-internal position, it necessarily takes RC-internal scope. This result suggests that Navajo IHRCs are amenable to analyses given to Japanese IHRCs (Hoshi 1995; Shimoyama 1999) but challenges claims by Faltz (1995) and Grosu (2012), who argue that $t$ 'áá 'attso 'all' invariably takes RC-external scope. We show that while IHRCs with t'áá 'attso do not have precisely the truth conditions expected for EHRCs, their truth conditions differ from what might be expected given a Shimoyama-style IHRC analysis (pace Grosu 2012). However, we consider one way to explain this behavior while maintaining surface scope for all Navajo quantifiers.
\end{abstract}

Keywords: Navajo, Dene, Athabaskan, internally-headed relative clauses, semantic fieldwork, quantification

\section{Introduction}

A prominent topic in the study of internally-headed relative clauses (IHRCs) crosslinguistically is whether they have the same truth conditions as minimally different externally-headed relative clauses (EHRCs). Work on Japanese (Hoshi 1995; Shimoyama 1999) and Korean (Kim 2007) demonstrates that IHRCs in these languages are truth-conditionally distinct from their EHRC counterparts:

a. Taro-wa [[Yoko-ga reezooko-ni kukkii-o hotondo

T.-TOP Y.-NOM refrigerator-LOC cookie-ACC most

irete-oita]-no]-o paatii-ni motte itta.

put-AUX-NO-ACC party-to brought

'Yoko put $\{\text { most of the cookies }\}_{1}$ in the refrigerator and Taro brought them $_{1}$ to the party.'

IHRC

* This project was developed in collaboration with Junko Shimoyama. Funding comes from a SSHRC Insight Grant (\#435-2015-0454) awarded to Junko Shimoyama and Keir Moulton. We thank Navajo consultant Ellavina Perkins for her patience and insight: any examples not otherwise cited should be credited to her. Any errors are our own. 
Navajo in the typology of internally-headed relatives

b. Taro-wa [[Yoko-ga reezooko-ni irete-oita] kukkii-o hotondo]

T.-TOP Y.-NOM refrigerator-LOC put-AUX cookie-ACC most paatii-ni motte itta.

party-to brought

'Taro brought to the party most of the cookies that Yoko had put in the refrigerator.'

EHRC

(Shimoyama 1999: (4), (5))

Shimoyama demonstrates that the Japanese sentence in (1a) can only convey that Yoko put the majority of the cookies in the fridge, and Taro brought all of those to the party. By contrast, (1b) can only convey that Taro brought the majority of the cookies Yoko put in the fridge. Shimoyama (1999) argues that this contrast arises because the quantified head in the IHRC (1a) is interpreted RC-internally. The IHRC is a closed sentence that is coordinated with the matrix clause. An Etype pronoun in the matrix clause refers to the maximal individual denoted by the IHRC. ${ }^{1}$ This is reflected in the translation of (1a) via coordinated root clauses.

However, Grosu (2012) argues that this analysis is not right for IHRCs in Navajo (Dene/Athabaskan; Na-Dene). Citing Faltz's (1995; 2000) translations and comments, Grosu argues that the universal quantifier t'áá 'attso 'all' associated with the internal head in (2) is obligatorily interpreted with RC-external scope.

[Łééchąa'í t'áá 'ałtso] 'ashkii deishxash]-ígíi

dog all boy PL.3OBJ.3SBJ.bite.PFV-IGII

nidahał'in.

PL.3SBJ.bark.IPFV

'All the dogs that bit the boy are barking.'

(Faltz 1995: 305 (106))

This paper presents fieldwork results that show that at least some Navajo quantifiers must take RC-internal scope when pronounced RC-internally. We focus on examples with 'atníídóó 'half' (3), which we found were accepted in contexts consistent with 'atníídóó having RC-internal scope (3a) but rejected in contexts consistent with RC-external scope (3b).

$$
\begin{aligned}
& \text { [Mary 'aghaa' 'ałnííd dóó yizdiz]-ęe } \\
& \begin{array}{lll}
\text { M. wool half } & \text { 3OBJ.3SBJ.spin.PFV-IGII A. }
\end{array}
\end{aligned}
$$

yiyííłchíí'.

3OBJ.3SBJ.dye.red.PFV

a. Internal 'half': Mary spun half of the wool. Alice dyed it. $\quad \checkmark(3)$

b. External 'half': Alice dyed half of the wool that Mary spun. \#(3)

1 See Grosu \& Landman (2012) for an alternative analysis of Japanese relative clauses. 
The paper has the following structure. Section 2 gives an overview of Navajo relative clauses and analyses by Platero (1974) and Willie (1989). We also present preliminary discussion of claims by Faltz (1995, 2000) and Grosu (2012) about quantifier scope in Navajo IHRCs. Section 3 presents elicitation evidence about the scope of 'atníl'dóó 'half' in (3). Section 4 reconsiders Grosu's (2012) claims about Navajo IHRCs with universal quantifiers: we claim that the truth conditions of sentences differ from those of English EHRCs. Section 5 concludes.

\section{Background on Navajo IHRCs}

\subsection{Basics of Navajo sentences and IHRCs}

Navajo verb words are morphologically complex structures that always bear markers indicating person and number of event participants (Young \& Morgan 1987). Lexical noun phrases can be used to add more information about event participants as in (4), but need not be included (5). The morphological marking on the verb does not vary with the presence of external noun phrases.

(4) Sam tít' yizloh.

S. horse 3OBJ.3SBJ.rope.PFV

'Sam roped the horse.'

(5) Yizloh.

3OBJ.3SBJ.rope.PFV

'S/he roped it/him/her.'

Navajo typically has SOV word order but OSV order is also attested, such as when the object has particular length, such as when the object is an IHRC (6)

[Mary 'aghaa' yizdiz]-ęę Alice yiyíílchíí'.

M. wool 3OBJ.3SBJ.spin.PFV-IGII A. 3OBJ.3SBJ.dye.red.PFV

'Alice dyed red the wool that Mary spun.'

The morphosyntax of Navajo relative clauses was first discussed in significant detail by Platero (1974). All relative clauses in Navajo bear a special morpheme at their right edge, variably realized as -ée (6), -áa (7a) or, most commonly, -ígí (7b). The morphemes - áa and -ée are preferred by speakers when the RC describes an event or state that held prior to speech time (Platero 1974; Smith, Perkins \& Fernald 2007), but -ígíi can be substituted (Ellavina Perkins, p.c.). To simplify, we use -ígíi in text and IGII in glosses to stand for all markers. ${ }^{2}$

2 The marker -ígí also marks clausal complements to certain verbs (Schauber 1979). It is crosslinguistically common to find the same marker on both IHRCs and clausal complements (Culy 1990; 
Navajo in the typology of internally-headed relatives
a. [Tł'ééạáá ' ashkii 'ałhạáa']-ạąa
yádoołtih.
last.night boy 3SBJ.snore.IPFV-IGII 3SBJ.speak.FUT
'The boy who was snoring last night will speak.'
b. [K'ad t'éiyá 'ashkii 'ałhạáá]-1́gíí yádoołtih.
now just boy 3SBJ.snore.IPFV-IGII 3SBJ.speak.FUT
'The boy who is snoring right now will speak.'

As Platero (1974) observes, (7) must be an IHRC: there is no conceivable syntactic parse in which 'ashkii 'boy' occupies a syntactic position external to the relative clause since 'ashkii is preceded by an expression tt'éédáa' 'last night' that cannot modify the future-marked main clause verb.

Apart from the presence of -ígí, Navajo relative clauses are indistinguishable from independent clauses. Navajo relative clauses contain no independent relative pronouns. Removing -ígí from an IHRC leaves a complete clause:

$$
\begin{aligned}
& \text { Tł'éédạáa ' ashkii 'ałhạác. } \\
& \text { last.night boy 3SBJ.snore.IPFV } \\
& \text { 'The boy was snoring last night.' }
\end{aligned}
$$

Note that Platero (1974) also gives examples of EHRCs in Navajo:

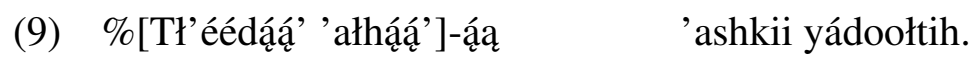
last.night 3SBJ.snore.IPFV-IGII boy 3SBJ.speak.FUT

'The boy who was snoring last night will speak.' (Platero 1974: 204 (11))

Platero notes that sentences like (9) are dispreferred in comparison with IHRCs. Other speakers go even further, however: Willie (1989) marks examples like (9) as ungrammatical and our consultant also rejected such examples (E. Perkins, p.c.).

\subsection{Previous treatments of Navajo relative clauses}

Platero (1974) and Willie (1989) present two different syntactic analyses of Navajo relative clauses. Platero (1974: (204)) proposes that a string like (10) underlies Navajo relative clauses, such that a copy of the head occurs in both clauses:

$$
\begin{aligned}
& \text { [Tł'éédạaá ' 'ashkii 'ałhạ́ạ́']-ạ́a 'ashkii yádoołtih. } \\
& \text { last.night boy 3SBJ.snore.IPFV-IGII boy 3SBJ.speak.FUT }
\end{aligned}
$$

Kim 2009). See Kim (2009) and Bogal-Allbritten \& Moulton (To appear) for a unified account of Korean kes, a marker with the same apparent distribution as -ígí. 
Platero writes that the copies are linked by a "relative connection" but does not elaborate on the nature of this connection. This account recalls (at least superficially) matching analyses of English relative clauses by Carlson (1977) and Sauerland (2003), among others, in which a silent operator mediates between the RC-external head and the RC-internal copy.

Willie (1989) presents a very different analysis of Navajo relative clauses. ${ }^{3}$ Willie observes that relative clauses do not require an overt lexical noun to serve as the head (11a). In such examples, the relative clause is translated as 'the one(s) who' or 'the one(s) that.' This is the standard strategy for forming new nouns (11b).

a. ['Ałháą́']-ígíí yádoołtih.

3SBJ.snore.IPFV-IGII 3SBJ.speak.FUT

'The one who is snoring will speak.'

b. [Ni' bítl'áahdi 'áhoot'eii

earth 3POSs.bottom.LOC conditions

ndeiłkaah]-ígíí

PL.3OBJ.3SBJ.investigate.IPFV-IGII

'those who investigate the bottom of the Earth' (geologists)

(Young \& Morgan 1987: 638)

Willie proposes that -ígí is a nominal head that can convert complete clauses into referential expressions. ${ }^{4}$ This is the function of -ígí regardless the presence of a lexical head noun within the relative clause. When a lexical head noun is present inside a relative clause (12b), the head introduced by -ígí is (somehow) identified with 'ashkii 'boy' (Willie 1989: 416).

a. [shizts'os]-yęę

1OBJ.3SBJ.kiss.PFV-IGII

'the one such that that s/he kissed me'

b. ['ashkii shizts'os]-yęę

boy 1OBJ.3SBJ.kiss.PFV-IGII

'the boy + the one such that he kissed me' (Willie 1989: 414 (25))

Neither Platero (1974) nor Willie (1989) discusses in detail the semantic implications of their proposals. However, their analyses suggest possible differences in the height at which the head (and any material associated with the head, such as modifiers or quantifiers) will be interpreted. For Platero, sentences with relative

3 Willie's proposal for IHRCs is part of her larger program to apply Jelinek's (1984) Pronominal Argument Hypothesis to Navajo, such that all lexical nouns are adjuncts that corefer to pronominal argument markers on the verb.

4 Willie does not discuss EHRCs since they are ungrammatical for her, as noted above. 
Navajo in the typology of internally-headed relatives

clauses always contain two copies of the head, regardless of which one is pronounced. We might predict, then, that the head and any associated material will be able to take scope outside of the relative clause, even when pronounced RCinternally. For Willie, by contrast, relative clauses are created by the attachment of -igíl to a closed sentence. As such, we predict that the head and any associated material will have RC-internal scope.

\subsection{Faltz, Grosu: Internal heads and quantifiers with external scope}

While they do not directly address Platero and Willie's analyses, Faltz $(1995,2000)$ and Grosu (2012) address the question of the height of interpretation for heads and quantifiers in Navajo relative clauses. They discuss the sentences in (13), in which the head nouns (tééchaq'í 'dog' (13a), chidí 'car' (13b)) and universal quantifier t'áá 'attso 'all' are pronounced in RC-internal position.

a. [Lééchąa'í t’áá 'ałtso] 'ashkii deishxash]-ígíi

$\operatorname{dog}$ all boy PL.3OBJ.3SBJ.bite.PFV-IGII nidahał'in.

PL.3SBJ.bark.IPFV

'All the dogs that bit the boy are barking.' (Faltz 1995: 305 (106))

b. [John Bill t'áá 'altso chidí yaa nayiisnii']-ęę

J. B. all car 3OBJ.from 3OBJ.3SBJ.buy.PFV-IGII

t'éiyaá nizhóniígo nídaajeeh.

only well PL.3SBJ.run.IPFV

'All the cars that John bought from Bill (and only those) run well.'

(Faltz 1995: 305 (107))

Faltz (1995, 2000) and Grosu (2012) both suggest that although pronounced RC-internally, the quantifier t'áá 'attso 'all' takes scope outside of the relative clause. This is reflected in Faltz's translations of (13) as EHRCs. Of (13a), Faltz writes that $t$ 'áa 'attso must not interpreted inside the relative clause "because the semantic interpretation of the relative clause alone would imply that all the dogs bit John" (Faltz 1995: 304), an interpretation which Faltz implies is unavailable for (13a). Similarly, Grosu asserts that (13b) conveys neither that all of John's cars were bought from Bill, or that John bought all of Bill's cars (Grosu 2012: 470).

On the basis of these observations, Grosu concludes that there is no difference in interpretation between Navajo IHRCs with universally quantified heads and "minimally different EHRCs." This sets Navajo apart from Japanese, where the truth conditions differ depending on where the quantifiers are pronounced. 
Bogal-Allbritten, Moulton

\subsection{Reviewing Faltz and Grosu}

There are several places where Faltz and Grosu's claims require further attention. First, while both assert that sentences like (13) have the same interpretation as minimally distinct EHRCs, they do not explicitly compare the relevant sentence pairs. Indeed, as noted above, it may not be possible to test sentences in which the nominal head is pronounced RC-externally, since most speakers reject such strings. However, our consultant accepted sentences like (14) in which the quantifier was pronounced in RC-external position. If the universal quantifier t'áa 'attso 'all' has RCexternal scope even when pronounced RC-internally, we might expect that (13a) is true in the same contexts as (14). We test such minimal pairs below.

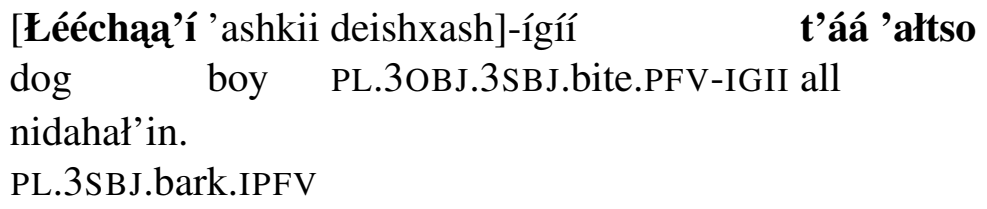

Second, the tools used to examine the truth conditions of (13) deserve a closer look. Both sentences are given translations into English with EHRCs, but it is not clear how these translations were elicited. As Matthewson (2004) notes, translations are at best partial clues about meaning: they may give an especially inaccurate or incomplete picture of a sentence's truth conditions if the language of translation (English) lacks a straightforward correlate to the construction of interest (IHRCs). We will discuss in detail all contexts that were used to elicit judgments.

Finally, Faltz and Grosu's discussion is restricted to IHRCs with the universal quantifier t'áá 'attso. As such, Grosu notes that he cannot say whether his proposed analysis will suffice for all Navajo IHRCs. We also believe that universal quantifiers are not an ideal for determining scope in sentences with relative clauses. The key examples from Shimoyama (1999) contain the proportional quantifier hotondo 'most' because its scope impacts truth conditions in a clear way.

a. IHRC (1a): 'Yoko put $\{\text { most of the cookies }\}_{1}$ in the refrigerator and Taro brought them 1 to the party.'

b. EHRC (1b): 'Taro brought to the party most of the cookies that Yoko had put in the refrigerator.'

We can construct pairs of contexts where one context (16a) verifies only the IHRC paraphrase while the other (16b) verifies only the EHRC paraphrase.

(16) a. IHRC only: Yoko put away only 8/10 cookies. Taro brought all 8 .

b. EHRC only: Yoko put away 10/10 cookies. Taro brought only 8 . 
Navajo in the typology of internally-headed relatives

However, a confound is presented by paraphrases with universal quantifiers. The hypothetical paraphrases in (17) for (13a) are based on Shimoyama (1999).

a. IHRC: ' $\{\text { All of the dogs }\}_{1}$ bit the boy. They ${ }_{1}$ are barking.'

b. EHRC: 'All of the dogs that bit the boy are barking.'

It is true that we can construct contexts in which only the EHRC paraphrase is verified (18): if (13a) is true in this scenario, then we can conclude that (13a) does not necessarily have a Shimoyama-style IHRC structure. The truth of (13a) in (18) could be taken as evidence for the possibility of RC-external scope by t'áá 'attso in Navajo (although we will reconsider this conclusion in section 4).

EHRC only: 8/10 dogs barking. All 8 bit the boy.

But there is no 'IHRC only' context parallel to (16a), which can unambiguously diagnose an IHRC structure for a sentence like (13a). Any context that verifies the IHRC paraphrase in (17a) will also verify the EHRC paraphrase in (17b): if it is true that 'all of the dogs bit the boy,' then there is equivalence between the sets all of the dogs and all of the dogs that bit the boy.

Because of the difficulties posed by universal quantifiers, our fieldwork first focused on the interpretation of Navajo relative clauses with proportional quantifier 'atnííd dóo 'half,' which should - and, we argue, do - differ clearly in their interpretation based on the quantifier's scope (section 3). Section 4 returns to IHRCs with t'áá 'attso 'all.'

\section{3 'Half': Interpreted RC-internally when pronounced RC-internally}

\subsection{Eliciting results for 'ałnií'dóó 'half'}

We examined the sentences in (19), which differ in whether the proportional quantifier 'atníi'dóó 'half' occurs clause internally (19a) or clause externally (19b). The consultant judged both word orders to be well-formed. ${ }^{5}$ If Faltz $(1995,2000)$ and Grosu (2012) are right that heads and associated material take obligatory RCexternal scope, we predict that (19a) and (19b) will both have the same truth conditions as the English sentence in (19c).

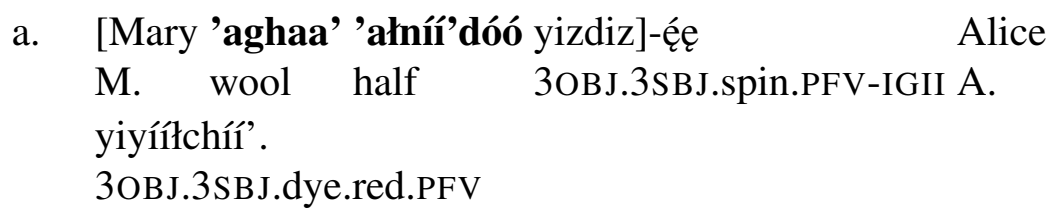

5 Since our consultant always rejected sentences with the nominal head pronounced RC-externally, we do not consider that configuration. 


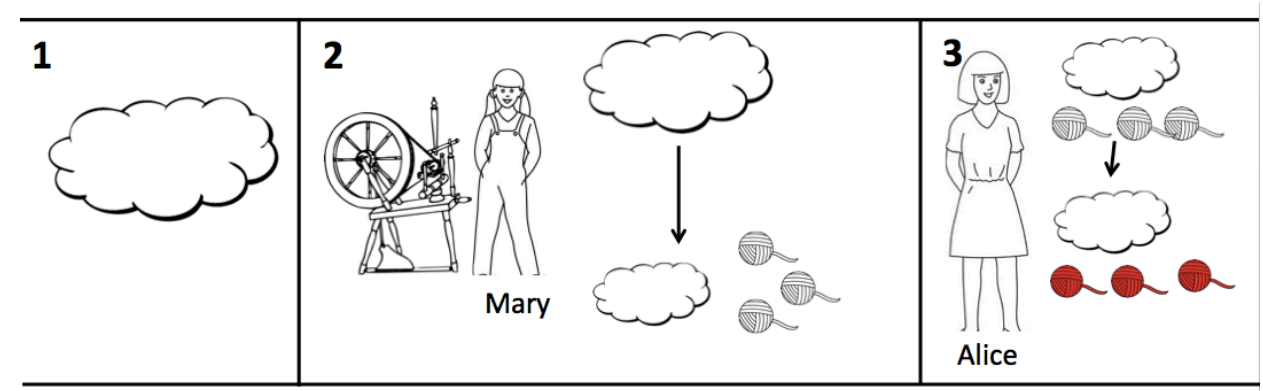

Figure 1 RC-internal interpretation of 'half'.

b. [Mary 'aghaa' yizdiz]-ęę

M. wool 3OBJ.3SBJ.spin.PFV-IGII half

yiyíítchíí'.

3OBJ.3SBJ.dye.red.PFV

c. Alice dyed red half of the wool that Mary spun. 'ałníídóó Alice

A.

We elicited judgments about these sentences with short storyboards, which are sequences of pictures designed to elicit or test constructions of interest (Burton \& Matthewson 2015). Storyboards allow the fieldworker to set up complex contexts with less interference from the translation language. We showed the consultant each storyboard and asked if (19a) and (19b) were natural continuations.

Figure 1 targets an RC-internal interpretation of 'atníi'dóo. The story begins with a quantity of wool (Panel 1), half of which Mary spins (Panel 2). Alice dyes red all of the spun wool but leaves the loose wool undyed (Panel 3). In this story, 'half' only applies to the wool involved in the relative clause event.

After viewing Figure 1, the consultant only accepted the sentence with RCinternal 'atníi'dóó (19a) and made the comment in (20a). She rejected the sentence with RC-external 'atníídóó (19b).

\section{Context: Figure 1}

a. (19a) accepted. Comment: "Half goes with the spinning."

b. \#(19b)

Figure 2 targets an RC-external interpretation of 'atníi'dóo. The story again begins with a quantity of wool (Panel 1) but all of the wool is spun by Mary (Panel 2). Alice subsequently dyes half of the spun wool, leaving the other balls of spun wool undyed (Panel 3). In this story, 'half' applies to the wool involved in the main clause event. 
Navajo in the typology of internally-headed relatives

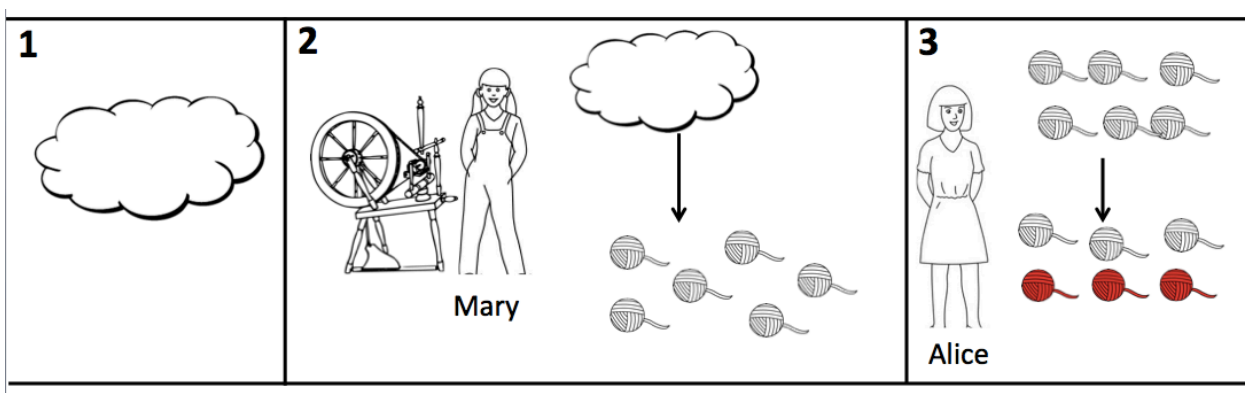

Figure 2 RC-external interpretation of 'half'

The consultant rejected the sentence with RC-internal 'atníl'dóó (19a) in the context of Figure 2. She accepted (19b) with 'atníídóó in RC-external position and gave the comment in (21b).

\section{Context: Figure 2}

a. \#(19a)

b. (19b) accepted. Comment: "[You would use this sentence because] you're saying that Alice only dyed half of the yarn."

To summarize the results for 'atníl'dóo, it appears that the height at which this quantifier is interpreted necessarily matches the height at which it is pronounced. This is not what we would expect under Grosu's proposal that quantifiers in Navajo relative clauses take external scope even when pronounced in RC-internal position.

\subsection{A Shimoyama-style account of IHRCs with 'half'}

The behavior of RCs with 'atníi'dóó matches the behavior of Japanese IHRCs with quantified heads (Hoshi 1995; Shimoyama 1999), where quantifiers in RCs are interpreted at the height at which they are pronounced. As such, an account based on Shimoyama (1999) seems promising for the Navajo IHRCs seen in this section. Before considering its applicability to Navajo, however, we will first review the key pieces of Shimoyama's account.

Shimoyama (1999) builds on Hoshi (1995) to propose that internal heads and associated quantifiers do not covertly raise out of relative clauses in Japanese. In a sentence like (22a), then, the quantifier dono 'every' takes scope within the IHRC, quantifying over all the newspapers in the relevant domain. The IHRC is interpreted as a closed sentence that is adjoined to the main clause at LF. A rough LF for (22a) is shown in (22b). 
a. Taro-wa [[ Hanako-ga dono sinbun-mo katte kita]-no]-o

T.-TOP H.-NOM every newspaper buy.came-NMLZ-ACC

tanani narabeta.

on.shelf placed

'Hanako bought every newspaper and Taro shelved them.'

b. [IHRC Hanako bought every newspaper] \& [ Taro shelved [DP no $\mathrm{P}_{3}$ ]]

The main clause contains an E-type pronoun (underlined) with internal complexity. Shimoyama (1999) takes the nominalizer no to be akin to a definite determiner, a maximalizing operator that takes as complement a contextually-supplied property variable $\mathrm{P}$ (type $\langle\mathrm{e}, \mathrm{t}\rangle$ ) and returns a maximal individual (23a). In this context, the assignment function $\mathrm{g}_{c}$ values $\mathrm{P}$ as the property of being newspapers bought by Hanako (23b). The maximal individual of which $\mathrm{P}_{3}$ holds is the object in the main clause $(23 \mathrm{c})$.

a. $\llbracket \mathbf{n o}\left(\mathrm{P}_{3}\right) \rrbracket=$ max. individual $a$ such that $\mathrm{P}(a)$

b. $\quad \mathrm{g}_{c}:=\left[3 \rightarrow \lambda \mathrm{x}_{e} . \mathrm{x}\right.$ is newspapers that Hanako bought $]$

c. $\quad \llbracket(22 b) \rrbracket \rightsquigarrow H$. bought every newspaper \& T. shelved the newspapers that $H$. bought

We can sketch an account of the same general shape for our Navajo sentence with RC-internal 'atníl'dóó repeated in (24a). As in Japanese, the IHRC is a closed sentence that moves at LF to be coordinated with the matrix clause (24b). In a context with an assignment function that includes the mapping in (24c), IGII 4 is interpreted as 'the wool that Mary spun.' (24d) gives the result.

a.

[Mary 'aghaa' 'ałníídóó yizdiz]-éę
$\begin{array}{lll}\text { M. wool half } & \text { 30BJ.3SBJ.spin.PFV-IGII A. }\end{array}$

yiyíítchíí'.

3OBJ.3SBJ.dye.red.PFV

'Mary spun half the wool, Alice dyed it red.'

b. [IHRC Mary spun half the wool] \& [ Alice dyed IGII 4 ]

c. $\mathrm{g}_{c}:=\left[4 \rightarrow \lambda \mathrm{x}_{e} . \mathrm{x}\right.$ is wool that Mary spun $]$

d. $\llbracket(24 a) \rrbracket \rightsquigarrow M$. spun half the wool \& A. dyed the wool that M. spun

The marker -igíl could be treated either as a maximalizing operator like Japanese no or perhaps as a pronoun corresponding to Shimoyama's free property-type variable P. In both cases -igii would remain in the matrix clause at LF. Both views are close to the kind of picture proposed by Willie (1989), who argued that -igíl is a nominalizer that is identified with the head of the relative clause. ${ }^{6}$

6 Treating -ígí as a property-denoting expression could help us to account for an apparently indefinite 
Navajo in the typology of internally-headed relatives

\section{Universally Quantified Heads}

\subsection{Eliciting results for 'all'}

We now turn to Navajo IHRCs with universal quantifiers. As we did with 'atnií'dóó, we compare (25a) with (25b), which differ only in the position of t'áa 'attso 'all.' Based on their discussion of other IHRCs with t'áa 'attso, we assume that Faltz and Grosu would assign (25a) and (25b) the truth conditions of English EHRC (25c).
a. [Sam Kî́' t’áá 'ałtso deizloh]-ạa
Tom
S. horse all PL3OBJ.3SBJ.rope.PFV-IGII T.
yída'diiłid.
PL.3OBJ.3SBJ.brand.PFV
b. [Sam tiú' deizloh]-ạ́ą t'áá 'altso Tom
S. horse PL.3OBJ.3SBJ.rope.PFV-IGII all T.
yída'diilid.
PL.3OBJ.3SBJ.brand.PFV
c. Tom branded all of the horses that Sam roped.

The storyboard in Figure 3 depicts the kind of contexts alluded to by Faltz and Grosu, where it is not the case that absolutely all entities in the context are involved in the event described by the relative clause. Panel 1 shows seven horses, three of which are roped by Sam (Panel 2). Tom then brands those three horses (Panel 3). The English EHRC (25c) is true in this context. The consultant also accepted both of the Navajo sentences (25a) and (25b) in this context.

\section{Context: Figure 3}

a. (25a) accepted.

b. (25b) accepted.

This pattern of judgments seems to agree with the predictions of Grosu (2012) and Faltz $(1995,2000)$. The felicity of $(25 \mathrm{a})$ is unexpected if the Navajo sentence is subject to Shimoyama's (1999) treatment of IHRCs with universal quantifiers (22b): 'Sam roped all of the horses and Tom branded them' is not true in Figure 3 since four of the horses were not roped.

IHRC discussed by Grosu (2012). In addition, if we treat -ígí as property-denoting, we could then analyze the quantifier-external examples as in (19b) as also involving LF movement of the IHRC, but a QP on -igii stranded in the matrix clause at LF:

(i) [IHRC Mary spun the wool] \& [ Alice dyed IGII half ] $\rightsquigarrow$ Mary spun the wool and Alice dyed half the wool that Mary spun. 


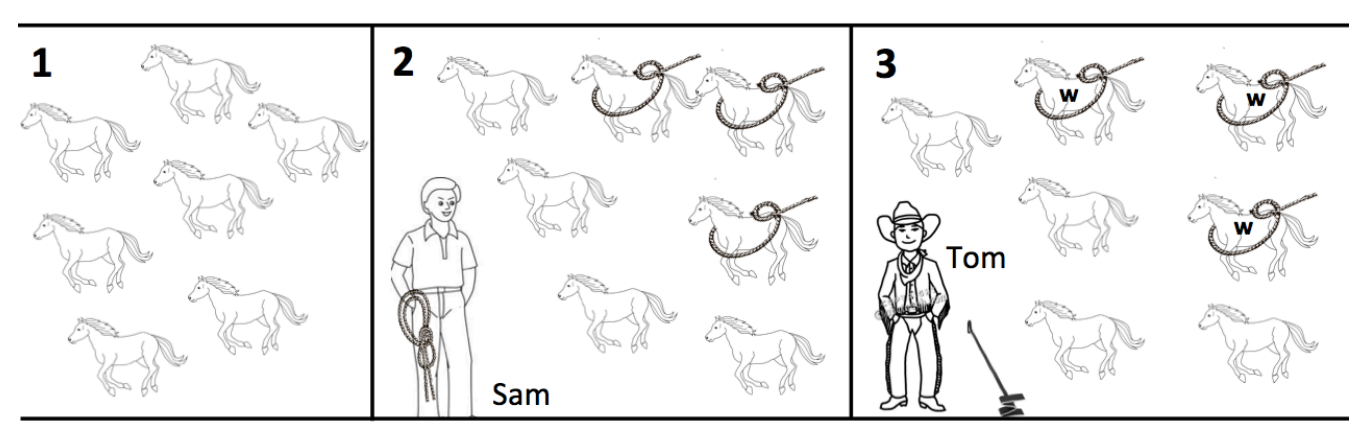

Figure 3 Seven horses in total: three horses roped and branded

At this point, we might be tempted to propose that Navajo quantifiers 'atníídóó and t'áá 'attso have different scope when pronounced in relative clauses: while 'atníídóó can be interpreted RC-internally, some factor forces t'áá 'ałtso to take high scope. Precedent for such divergent quantifier behavior comes from Hastings (2004), who demonstrates for Imbabura Quechua that while all quantifiers can be pronounced RC-internally, only weak quantifiers like pisi 'a little' are interpreted RC-internally; strong quantifiers like tukuy 'all' always has RC-external scope.

A proposal of this shape faces several possible problems. To start, Hastings's account relies on the distinction between weak and strong quantifiers to explain the scopal facts in Imbabura Quechua, but it is not clear that 'atníi'dóo 'half' is a weak quantifier in Navajo, or whether a weak/strong distinction quantifier distinction even operates in the language.

We have also identified another reason to doubt that Navajo sentences with RCinternal t'áá 'attso (25a) have the truth conditions of EHRCs like (25c). We identified one type of context where judgments for the Navajo sentence with RC-internal t'áá 'attso (25a) diverged from judgments for sentences with the universal quantifier in RC-external position. In Figure 4, there are again seven horses (Panel 1), three of which are roped by Sam (Panel 2). This time, however, Tom brands two other horses in addition to the three that were roped (Panel 3).

Both the English EHRC (25c) and the Navajo sentence with RC-external t'áa 'attso (25b) were accepted without hesitation in this context. However, the response to $(25 \mathrm{a})$ in this context was more complex, as shown by the comments shown below.

\section{Context: Figure 4}

a. \#(25a): "Sounds like you're saying Sam roped all of the horses and Tom branded them...It's just okay if you don't worry about the plus two others [that got branded]. Or say '....and then he roped two more.'" 


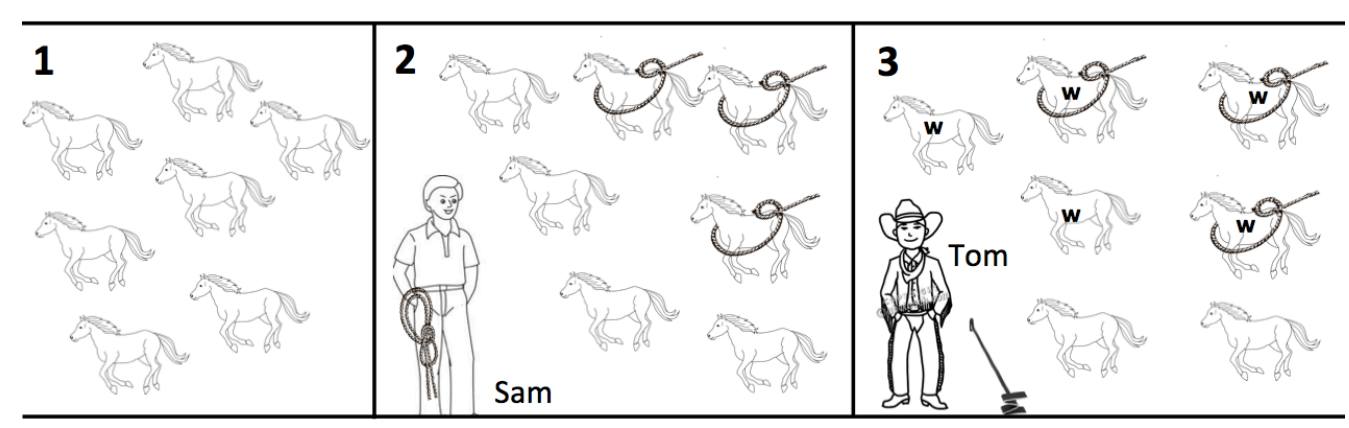

Figure 4 Seven horses total: three horses roped, five horses branded

b. (25b) accepted.

We note that the same judgment was elicited for (25a) in modified versions of Figure 4 that contained different numbers of horses but where, in every case, the roped horses were a subset of the branded horses. Each time, the consultant gave a comment that highlighted the inequality of the two sets.

To summarize, the Navajo sentence with RC-external t'áá 'attso 'all' (25b) seems to have the same truth conditions as the English EHRC in (25c). Furthermore, the Navajo sentence with RC-internal t'áá 'attso (25a) was felicitous in contexts where it was not the case that all of the horses were roped, in accordance with Faltz (1995, 2000) and Grosu (2012). However, while (25a) does not have precisely the truth conditions expected under a Shimoyama-style account, neither does it have precisely the truth conditions of sentences with the universal quantifier in RC-external position. Notably, pronouncing t'áá 'attso RC-internally seemed to require equivalence between the individuals described by the relative clause and the individuals that exhaustively satisfy the main clause.

Before turning to possible explanations for this observation, we observe that Navajo may not be the only Dene language for which such judgments arise. The northern Dene language Tłicho allows quantifiers - including universal quantifier hazeQ̀ (28) - in RC-internal position (Mantla, Moulton \& Saxon In prep.). Note that Ticho marks relative clauses with a nominalization suffix, whose exponent surfaces as lengthening of the verb stem's final vowel (Saxon 2000). We gloss this marker as IGII for consistency with our discussion of Navajo.

Leslie elà hazọ̀ whehtsị-i daele

Leslie boat all PFV.make-IGII IPFV.float

'All the boats Leslie made are floating.' (Mantla et al. In prep.)

A storyboard was presented to the Tłıcho language consultant which depicted 
all of Leslie's boats floating on the water, as well as one additional boat not made by Leslie on the water and the remainder of boats not made by Leslie on the shore. In this context it is true that all of the Leslie-made boats are floating (an external interpretation of 'all'). Interestingly, however, the consultant rejected (28) in this context, pointing out that there is a boat on the water that is not made by Leslie. The consultant offered (29) instead, adding sentential negation le.

$$
\text { Leslie elà hazọ̀ whehtsị-i daele-le }
$$

Leslie boat all PFV.make-IGII IPFV.float-NEG

'It is not the case that all the boats Leslie made are floating.'

(Mantla et al. In prep.)

At present we have not yet compared (28) with a minimally-different example where the quantifier is RC external in Tłcho. However, the comment in (28) suggests that there must be equivalence between the individuals described by the relative clause (Leslie-made boats) and the individuals that exhaustively satisfy the matrix predicate (floating boats). The judgments for Tłıcho, then, are intriguingly similar to what we observed for Navajo. ${ }^{7}$

\subsection{The illusion of high scope by $t$ 'áá 'attso 'all'}

The complexity of the results for t'áá 'attso 'all' contrasts with the behavior of RCinternal 'atnî́' dóo 'half,' which seems straightforwardly amenable to Shimoyama's (1999) analysis of IHRCs. On the other hand, when t'áá 'attso occurs RC-internally, the truth conditions are not precisely what we would expect for either IHRCs or EHRCs with universal quantifiers (30):

[Sam tiú' t'áá 'ałtso deizloh]-ạą $\quad$ Tom

S. horse all PL3OBJ.3SBJ.rope.PFV-IGII T.

yída'diiłid.

PL.3OBJ.3SBJ.brand.PFV

a. Set of branded horses must equal set of roped horses (not a requirement of EHRCs).

b. Set of roped horses can be smaller than domain of horses in context (not expected to be permitted for IHRCs).

We will not give a full solution to the puzzle posed by t'áá 'attso, but instead describe one conceivable direction and highlight potential challenges for it. We start with the observation that when (30) occurs in a context like Figure 3 - where

7 In some respects, these judgments resemble quantifier spreading in the acquisition literature (Philip 1995), although we have not explored this connection deeply. 
we own seven horses and three are both roped and branded - it is not true that all horses in the set of owned horses were roped, but it is true that all horses in a smaller set of horses — the branded horses — were roped. Could t'áá 'attso in 3 be quantifying over this more restricted set of horses?

We must, of course, have in general a mechanism for restricting the domain of quantifiers (Westerståhl 1985; von Fintel 1994; inter alia). If (31) is uttered in a context where we own seven horses, the sentence conveys that Sam roped members of the restricted set of horses (C), not that he roped every horse in the world.

$$
\begin{aligned}
& \text { Sam tíí' táá 'ałtso }{ }_{C} \text { deizloh. } \\
& \text { S. horse all } \quad \text { PL.3OBJ.3SBJ.rope.PFV } \\
& \text { 'Sam roped all } C \text { the horses.' }
\end{aligned}
$$

An appeal to saliency might help us to explain the restricted domain of t'áá 'attso. At the point in Figure 3 where the sentence with t'áá 'attso occurs, Tom's branding has just been mentioned, making the three horses very salient and topical, perhaps even more so than the seven horses. When uttered in such a context, then, perhaps $\mathrm{C}$ is equal to the set of branded horses. In another context - such as Figure 4, discussed below - the valuation of $\mathrm{C}$ could be different.

If domain restriction can works this way, then, it would be possible to apply Shimoyama's (1999) analysis of IHRCs, which we sketched for Navajo in section 3.2. As before, the matrix object position would be filled by -IGII (32a). If -ígí is maximalizing like Japanese no, then we correctly predict the desired equivalence between the branded horses and the roped horses.

a. [IHRC Sam roped all $C$ the horses] \& [ Tom branded IGII 2 ]

b. $\mathrm{g}_{c}:=\left[2 \rightarrow \lambda \mathrm{x}_{e} . \mathrm{x}\right.$ is a horse that Sam roped $]$

We now turn to the infelicity of (30) in Figure 4. Here, a natural value for the domain C of t'áá 'attso be the five branded horses, since that is the last set of horses mentioned before the sentence with t'áá 'attso is uttered. But then if this were the domain for the quantifier in the IHRC, it is not true that Sam roped all of those five horses in Figure 4, and (30) is accordingly rejected. If it is possible at all for $\mathrm{C}$ to be equated to just three horses, this seems to take some work, as indicated by the consultant's comment about "ignoring" the other horses.

Under the story we have described so far, the 'high scope' of t'áá 'attso claimed by Faltz (1995, 2000) and Grosu (2012) is an illusion. The reading of interest results from a domain of quantification that is restricted in a special way. The quantifier still takes scope internal to the relative clause. Applying this idea to the familiar 'cars' example, we can imagine (33) being uttered in a context where the set of cars that run well is salient, such that this is the domain of quantification for t'áa 'attso, 
rather than the set of all cars on the lot.

$$
\begin{aligned}
& \text { [John Bill t'áá 'ałtso chidí yaa nayiisnii']=ęę t'éiya } \\
& \text { John Bill all car 3OBJ.from 3OBJ.3SBJ.buy.PFV=IGII only } \\
& \text { nizhónígo nidaajeeh. } \\
& \text { well 3S.run.plural.actors.IPFV }
\end{aligned}
$$

Translation from Faltz and Grosu: 'All the cars that John bought from Bill (and only those) run well.'

The morphology of Navajo t'áá 'attso might give us a reason to consider an account that relies heavily on quantifier domain restriction. Marti (2003) argues that $\mathrm{C}$ should be represented formally as a covert pronoun. We observe that Navajo t'áá 'ałtso always bears morphological markers for person and number (34), just like those found on verbs. We would like to speculate that the pronominal marking on forms of t'áá 'attso in (33) is an overt realization of Marti's proposed pronoun.

$$
\begin{aligned}
& \text { a. t'áá 'attso 'all of them' } \\
& \text { b. t'áá 'aniiltso 'all of us' } \\
& \text { c. t'áá 'anóttso 'all of you' }
\end{aligned}
$$

3SBJ: $\varnothing$

1PL.SBJ: iid

2PL.SBJ: $o h$

The presence of pronominal marking is apparently relatively unique to t'áá 'attso: 'ałníídóó 'half,' for instance, does not have such marking. Thus, we do not predict 'atníi'dóó to exhibit the effects of an exceptionally restricted domain that we claim hold for t'áá 'attso.

An English paraphrase with meaning similar to what we intend is all them horses, where the pronoun them can restrict the domain of quantification to a salient subset of horses in the context. The contexts presented in Figure 3 and Figure 4 differ in what subsets are made salient. In the English paraphrase of Figure 3 (35), English they and all them horses can pick out a subset of horses in the global domain, i.e. the three roped horses. In the English paraphrase of Figure 4 (36), by contrast, them preferentially picks out five horses horses in the domain; reference to the subset of three is anomalous.

Figure 3: English version

There are seven horses on our ranch. Sam roped three of them. Tom branded those threee horses. They ${ }_{j} /$ all them $_{j}$ horses were Clydesdales.

$$
\mathrm{j}=\text { the } 3 \text { horses }
$$


Navajo in the typology of internally-headed relatives

Figure 4: English version

Sam roped three horses. Tom branded those three horses plus two others. They $_{j} /$ all them ${ }_{j}$ horses were Clydesdales.

$\# \mathrm{j}=$ the three horses; $\mathrm{j}=$ the five horses

However, there is a problem. This account would, ideally, apply to all uses of t'áá 'attso, even outside of IHRCs. However, (37) shows that t'áá 'attso is rejected apparently because a smaller salient (most recently mentioned) set of horses (three branded) cannot function as the domain of quantification.

a. Context: Figure 3. Seven horses in total. Three horses are roped by Sam, then those three horses branded by Tom.

b. \#Sam łị̂' táá 'ałtso deizloh.

S. horse all PL.3OBJ.3SBJ.rope.PFV

'Sam roped all the horses.'

Comment: “This isn't good because he didn't rope all the horses, he just roped three of them."

This suggests that even if a domain restriction approach is appealing, it must somehow be restricted to quantifiers inside IHRCs.

\section{Conclusion}

We have considered the semantics of Navajo IHRCs with quantified heads. We argue that 'atníi'dóó 'half' unambiguously takes scope RC-internally. As such, any claim that quantifiers scope outside of relative clauses (Faltz 1995, 2000; Grosu 2012) is not universally valid in Navajo. We also presented new elicitation data about the scope of $t$ 'áá 'attso 'all,' which was the original focus of Faltz and Grosu (2012)'s claims. We demonstrated that while IHRCs with t'áá 'attso do not have precisely the truth conditions expected for EHRCs, their truth conditions differ from what might be expected given a Shimoyama-style IHRC analysis. However, we presented one way in which we might reconcile our observations with a Shimoyamastyle account by manipulating the domain of t'áá 'attso.

\section{References}

Bogal-Allbritten, Elizabeth \& Keir Moulton. To appear. Nominalized clauses and reference to propositional content. In Rob Truswell (ed.), Sinn und Bedeutung 21, 1-18.

Burton, Strang \& Lisa Matthewson. 2015. Targeted construction storyboards in 
semantic fieldwork. In M. Ryan Bochnak \& Lisa Matthewson (eds.), Methodologies in Semantic Fieldwork, 135-156. Oxford: Oxford University Press.

Carlson, Greg N. 1977. Amount relatives 58 3, 520-542. doi:10.2307/413175.

Culy, Christopher. 1990. The syntax and semantics of internally-headed relative clauses. Palo Alto, CA: Stanford University $\mathrm{PhD}$ dissertation.

Faltz, Leonard M. 1995. Towards a typology of natural logic. In Emmon Bach, Eloise Jelinek, Angelika Kratzer \& Barbara Partee (eds.), Quantification in Natural Languages, 271-319. Dordrecht: Kluwer.

Faltz, Leonard M. 2000. A semantic basis for Navajo syntactic typology. In Theodore Fernald \& Paul Platero (eds.), The Athabaskan Languages: Perspectives on a Native American Language Family, 28-50. Oxford: Oxford University Press.

von Fintel, Kai. 1994. Restrictions on quantifier domains. Amherst, MA: University of Massachusetts Amherst PhD dissertation.

Grosu, Alexander. 2012. Towards a more articulated typology of internally headed relative constructions: The semantics connection. Language and Linguistics Compass 6(7). 447-476. doi:10.1002/lnc3.346.

Grosu, Alexander \& Fred Landman. 2012. A quantificational disclosure approach to Japanese and Korean internally headed relatives. Journal of East Asian Linguistics 21(2). 159-196. doi:10.1007/s10831-011-9086-z.

Hastings, Rachel Elizabeth. 2004. The syntax and semantics of relativization and quantification: The case of Quechua. Ithaca, NY: Cornell University PhD dissertation.

Hoshi, Koji. 1995. Structural and interpretive aspects of head-internal and headexternal relative clauses. Rochester, NY: University of Rochester $\mathrm{PhD}$ dissertation.

Jelinek, Eloise. 1984. Empty categories, case, and configurationality. Natural Language and Linguistic Theory 2(1). 39-76. doi:10.1007/bf00233713.

Kim, Min-Joo. 2007. Formal linking in internally headed relatives. Natural Language Semantics 15(4). 279-315. doi:10.1007/s11050-007-9020-0.

Kim, Min-Joo. 2009. E-type anaphora and three types of kes-construction in Korean. Natural Language and Linguistic Theory 27(2). 345-377. doi:10.1007/s11049-009-9065-5.

Mantla, Rosa, Keir Moulton \& Leslie Saxon. In prep. Report on quantifiers in Tłicho internally-headed relatives (working title). Ms., University of Victoria and Simon Fraser University.

Marti, Luisa. 2003. Contextual variables as pronouns. In Robert B. Young \& Yuping Zhou (eds.), Semantics and Linguistic Theory (SALT) 13, 240-257. Cornell University, Ithaca, NY: CLC Publications.

Matthewson, Lisa. 2004. On the methodology of semantic fieldwork. International 
Navajo in the typology of internally-headed relatives

Journal of American Linguistics 70(4). 369-415. doi:10.1086/429207.

Philip, William. 1995. Event quantification in the acquisition of universal quantification. Amherst, MA: University of Massachusetts Amherst PhD dissertation.

Platero, Paul. 1974. The Navajo relative clause. International Journal of American Linguistics 40(3). 202-246. doi:10.1086/465313.

Sauerland, Uli. 2003. Unpronounced heads in relative clauses. In Kerstin Schwabe \& Susanne Winkler (eds.), The Interfaces: Deriving and Interpreting Omitted Structures, 205-226. Amsterdam: John Benjamins.

Saxon, Leslie. 2000. Head-internal relative clauses in Dogrib (Athapaskan). In Andrew Carnie, Eloise Jelinek \& MaryAnn Willie (eds.), Papers in Honor of Ken Hale (Working Papers on Endangered and Less Familiar Languages 1), 93-108. Cambridge, MA: MITWPL.

Schauber, Ellen. 1979. The syntax and semantics of questions in Navajo. Outstanding Dissertations in Linguistics. Champaign-Urbana: Garland Press.

Shimoyama, Junko. 1999. Internally headed relative clauses in Japanese and E-type anaphora. Journal of East Asian Linguistics 8(2). 147-182. doi:10.1023/a:1008338020411.

Smith, Carlota, Ellavina Perkins \& Theodore Fernald. 2007. Time in Navajo: Direct and indirect interpretation. International Journal of American Linguistics 73(1). 40-72. doi:10.1086/518334.

Westerståhl, Dag. 1985. Determiners and context sets. In Johan van Benthem \& Alice ter Meulen (eds.), Generalized Quantifiers in Natural Language, 47-71. Dordrecht: Foris.

Willie, MaryAnn. 1989. Why there is nothing missing in Navajo relative clauses. In Eung-Do Cook \& Keren Rice (eds.), Athapaskan Linguistics: Current Perspectives on a Language Family (Trends in Linguistics. State-of-the-Art Reports 15), 265-315. Berlin: Mouton de Gruyter.

Young, Robert \& William Morgan. 1987. The Navajo Language. Albuquerque, NM: University of New Mexico Press.

Elizabeth Bogal-Allbritten

Department of Philosophy, Linguistics, Theory of Science

University of Gothenburg

Olof Wijksgatan 6

41255 Göteborg Sweden

elizabeth.bogal-allbritten@gu.se
Keir Moulton

Department of Linguistics

University of Toronto

Sidney Smith Hall, 4th floor 100 St. George St.

Toronto, ON, Canada, M5S 3G3

keir.moulton@utoronto.ca 